\title{
Understanding the Potential of U-FAST Sintering Process - An Overview
}

ISSN: 2578-0255

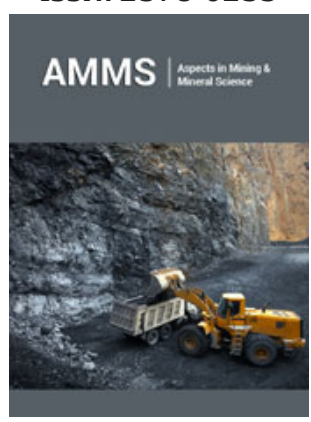

*Corresponding author: Raihan Rumman, Institute for NanoScale Science and Technology, Flinders Microscopy and Microanalysis, South Australia

Submission: 監 May 16, 2019

Published: 階June 20, 2019

Volume 3 - Issue 1

How to cite this article: Schembri J, Kaur S, Oskouei R, Rosinski M, Ghomashchi R, et al . Understanding the Potential of U-FAST Sintering Process - An Overview. Aspects Min Miner Sci.3(1). AMMS.000555.2019. DOI: 10.31031/AMMS.2019.03.000555.

Copyright@Raihan Rumman, This article is distributed under the terms of the Creative Commons Attribution 4.0 International License, which permits unrestricted use and redistribution provided that the original author and source are credited.

\author{
Schembri J' ${ }^{1}$, Kaur $\mathbf{S}^{1}$, Oskouei $\mathbf{R H}^{1}$, Rosinski $\mathbf{M}^{2}$, Ghomashchi $\mathbf{R}^{3}$ and Rumman \\ $\mathbf{R}^{4 *}$ \\ ${ }^{1}$ College of Science and Engineering, Flinders University, South Australia \\ ${ }^{2}$ GeniCore, Poland \\ ${ }^{3}$ School of Mechanical Engineering, The University of Adelaide, South Australia \\ ${ }^{4}$ Institute for NanoScale Science and Technology, Flinders University, South Australia
}

\begin{abstract}
As Tungsten carbide has a number of desired mechanical properties, including temperature resistance, high strength and toughness, which are suitable for industrial cutting tools therefore it is receiving great interest in cutting industry. One of the effective methods for the synthesis of cemented carbide is powder metallurgy. Sintering, a critical part of $\mathrm{P} / \mathrm{M}$ is occurred by pressing the powder into die and then heat is provided for a period of time until the sintering temperature reaches. Numerous conventional sintering methods were used to prepare tungsten carbide such as vacuum sintering and microwave sintering. The conventional methods are time consuming and require high temperature and high pressure. Some of these issues are resolved by current sintering methods such as spark plasma sintering by reducing the overall time of process and use of commercial grain growth inhibitors. Still, there are challenges that need more research in terms of sintering method that can produce binderless WC. In this study, along with the overview of several conventional and modern sintering processes, upgraded field assisted sintering technology (U-FAST) has been discussed from the perspective of manufacturing carbides. Technical details and microstructural features of U-FAST sintered WC are discussed.
\end{abstract}

Keywords: Sintering; U-FAST; Tungsten carbide; Microstructure; Conventional sintering

Abbreviations: U-FAST: Upgraded Field Assisted Sintering Technology; SEM: Scanning Electron Microscope; SPS: Spark Plasma Sintering; PPS: Pulse Plasma Sintering; ANFF: Australian National Fabrication Facility

\section{Introduction}

Powder metallurgy has been around for more than a century and has been expanding mainly due to its economical processing, unique properties and captive processes [1]. Powder metallurgy has been proven to be an effective method for producing hard materials, including carbides [2]. Metal alloys with any composition can be produced by using powders with the desired purity and fineness [3]. Due to the modern alloy constitution relying mainly on X-ray investigation, the alloys being in powder form is beneficial. Powder metallurgy allows the alloys to be examined, determining the exact phases present, before they undergo sintering [3]. In conventional sintering methods, the heat is transferred to the material using conduction, radiation and convection [4]. The material is heated from the outside causing the surface and the cross section to be heated at different rates, which creates a non-uniform heating [4]. The time to heat a material up to the desired temperature using the conventional sintering methods is long, into the hundreds of minutes [4]. Although the conventional methods have been used for over a century, other methods are needed to increase the efficiency and properties of the sintered material.

Modern sintering methods such as vacuum, microwave and plasma sintering are more efficient than the conventional methods due to their increased and more uniform heating rates [5]. Although these methods are better than conventional sintering they still yield undesirable grain growth. In carbides, if the grain growth can be controlled during heating and cooling cycle of sintering, mechanical properties can be enhanced [6]. WC has much 
greater qualities when it is sintered using nanoscale powder. WC powder can be reduced from micron/submicron size to nanosized by mechanical ball milling. This can achieve up to $10 \mathrm{~nm}$ sized powders over a large period of time [6,7]. Nanocrystalline WC-Co powders lose their nanoscale characteristics upon sintering due to extremely rapid grain growth during sintering; therefore, grain growth inhibitors are used [5]

Upgraded Field Assisted Sintering Technology (U-FAST) is a new sintering technique developed in Poland from a company known as GeniCore. The process is a step up to the SPS technology dedicated to powder materials' sintering. This technology uses an impulse power supply similar to that of SPS, however, it allows for a much higher voltage to be reached [8]. The U-FAST technology allows for full densification in a much shorter period of time and lower temperature when compared to the other sintering methods. In the fabrication of pure WC samples, no grain growth inhibitors or binding materials were present when sintering using U-FAST [8]. This technology is able to benefit from short current impulses and eliminates the capacitor battery circuit and spark gap of low stability in the energy supply circuit [8]. The materials produced using the U-FAST technology have very minimal grain growth even when using nanocrystalline and submicron powders [8]. This paper presents an overview of conventional and modern sintering processes along with their advances in $\mathrm{P} / \mathrm{M}$ and adds some excellent achievements of the U-FAST process in manufacturing WC samples without binders or any commercial grain growth inhibitors.

\section{Experimental Procedure}

The raw materials used in this study were of three different sizes of pure WC particles. The particles were commercially purchased from Taegu Tec in South Korea and may have been milled as part of production. Details of the initial particles are given in Table 1. Sintered samples were fabricated using the initial particles without any commercial grain growth inhibitors. No binders were used as part of the composition. The three different sizes of WC powders were then sintered using U-FAST.

Table 1: Details of initial WC particles used in U-FAST process.

\begin{tabular}{|c|c|c|c|c|}
\hline Sample & Particle size & Composition & Particle Shape & Spherical \\
\hline 1 & $100 \mathrm{~nm}$ & WC & Spherical & Unmilled after purchase \\
\hline 2 & $500 \mathrm{~nm}$ & WC & Spherical & Unmilled after purchase \\
\hline 3 & $1-3 \mu \mathrm{m}$ & WC & Unmilled after purchase \\
\hline
\end{tabular}

Table 2: The list of parameters used in U-FAST process.

\begin{tabular}{|c|c|}
\hline Internal dia. Of die & $19.5 \mathrm{~mm}$ \\
\hline External dia. Of die & $40 \mathrm{~mm}$ \\
\hline Temperature & $2000^{\circ} \mathrm{C}$ \\
\hline Heating Rate & $100{ }^{\circ} \mathrm{C}$ \\
\hline Cooling Rate & $100{ }^{\circ} \mathrm{C}$ \\
\hline Holding Time & $5 \mathrm{~min}$ \\
\hline Load & $15 \mathrm{KN}$ \\
\hline Vacuum Pressure & $5 \times 10 \mathrm{e}-5 \mathrm{mbar}$ \\
\hline Pre-sintering Pressure & 1 Tonn \\
\hline
\end{tabular}

Before sintering, the WC powders were manually pressed with 1 Tonn to generate the green samples. The process started by pouring powder into a graphite mould. Once the green samples were obtained. The die along with the green samples was placed in the U-FAST chamber. Then chamber was closed and heat source - a pulsing electric current was turned on. Once enough energy and heat was applied, the powder was compressed with $15 \mathrm{KN}$ load. The temperature of $2000{ }^{\circ} \mathrm{C}$ was used and the processing pressure in vacuum chamber was $5 \times 10^{\mathrm{e}-5} \mathrm{mbar}$. The parameters used for the process are mentioned in the (Table 2) below: Three discs were prepared with $19.5 \mathrm{~mm}$ diameter and $2 \mathrm{~mm}$ thickness. All the fabricated discs were manually cut into quarters by using diamond blade saw to mount cross-section surface along with the top surface. Then polishing was done on the mounted sample using a Tegramin 25 polishing machine (Struers). The samples were then etched to remove the deformed layer deposited during grinding and polishing also to reveal the microstructural detail of the polished mount or the crystalline structure of the sample. The samples were etched using Murakami reagent (10gm Potassium ferricyanide, $10 \mathrm{gm} \mathrm{NaOH}$ and $100 \mathrm{ml}$ of water) for $80-120$ seconds. The observation of microstructure of the samples was done with the help of an FEI F50 Scanning Electron Microscope (SEM) having an EDS analyser.

\section{Advances in Sintering Techniques in Manufacturing Materials}

\section{Microwave sintering versus conventional sintering}

The work by Breval et al. [9] compares the microwave and conventional sintering for WC-Co samples. In the conventional sintering the heating starts from surface, which thermally conducts from heating element to holding vessel and from outside to inside of the sample, thus it takes a considerable amount of time. However it was found in the study that in microwave sintering the heating is caused by oscillations of free electrons in microwave oven at high frequency microwave $(\sim 2.45 \mathrm{GHz})$ in cobalt, free carbon and of ions in WC $[10,11]$. Microwave sintering needs only minutes to complete the sintering because the thermal equilibrium reaches fast, while conventional sintering takes several hours due to thermal gradient from the surface to the centre of the sample. Hence the grain growth is less in microwave compared to conventional sintering.

The same initial powder was sintered in both the conventional furnace and in the microwave furnace at $2.45 \mathrm{GHz}$. WC- $6 \mathrm{wt} \%$ Co was used as raw material. Conventional sintering was performed at $1450{ }^{\circ} \mathrm{C}$ for approximately $1 \mathrm{~h}$ with up- and down-ramps in the 
order of 6-20h and microwave sintering was performed at 1300 $1450{ }^{\circ} \mathrm{C}$ for approx. $10 \mathrm{~min}$ with up- and down-ramps in the order of $60-90 \mathrm{~min}$. The micrographs (Figure 1) had shown that the grain size is smaller in microwave-sintered samples as compared to conventional sintered. It was also pointed out that by using microwave sintering fine grain growth can be achieved without using any growth inhibitors that usually degrade the mechanical properties of material. Also, the microwave-sintered samples achieved 1-5GPa better hardness than conventional method. The advantage of microwave sintering over conventional is its better grain growth even in shorter time and lower temperature.
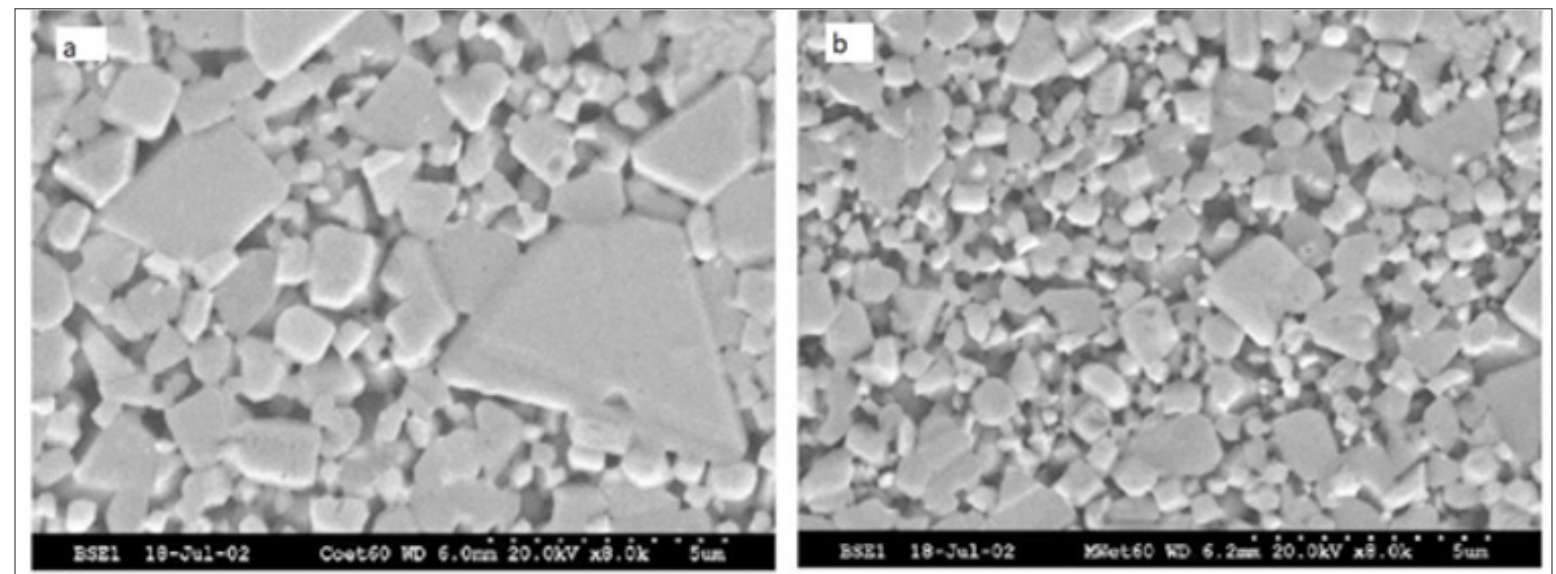

Figure 1: SEM images of WC/Co: a) conventionally sintered and b) microwave sintered [9].

\section{Vacuum sintering}

Liang et al. [12] synthesized WC-CO cemented carbide by vacuum sintering. The composition included WC (99.5wt. \%), Co (99.9wt. \%), VC (99wt. \%) and $\mathrm{Cr}_{3} \mathrm{C}_{2}$ (99wt. \%). The disk shaped green sample was prepared with $100 \mathrm{MPa}$ of pressure by pressing the dried powder. Also, the required amount of $5 \mathrm{wt}$. \% solution of PVA was added as a binder. Then sintering was done at 1280 ${ }^{\circ} \mathrm{C} \sim 1400{ }^{\circ} \mathrm{C}$ in vacuum sintering furnace with pressure applied under $1 \mathrm{~Pa}$. XRD analysis has shown that only WC and Co3W3C $(\gamma-$ phase) were present with a relative density of over 95\%. (Figure 2) shows the microstructure of the WC-Co cemented carbide with different wt. \% of Co. The microstructure was dense and well distributed including some bulky grains. It was found that in this method the hardness was increased with increasing temperature because the relative density increases with temperature. However, the grain size also increased with the highly increased temperature. The issues associated with this method are that it is a slow process and comes with the additional step of preparing green sample before sintering.

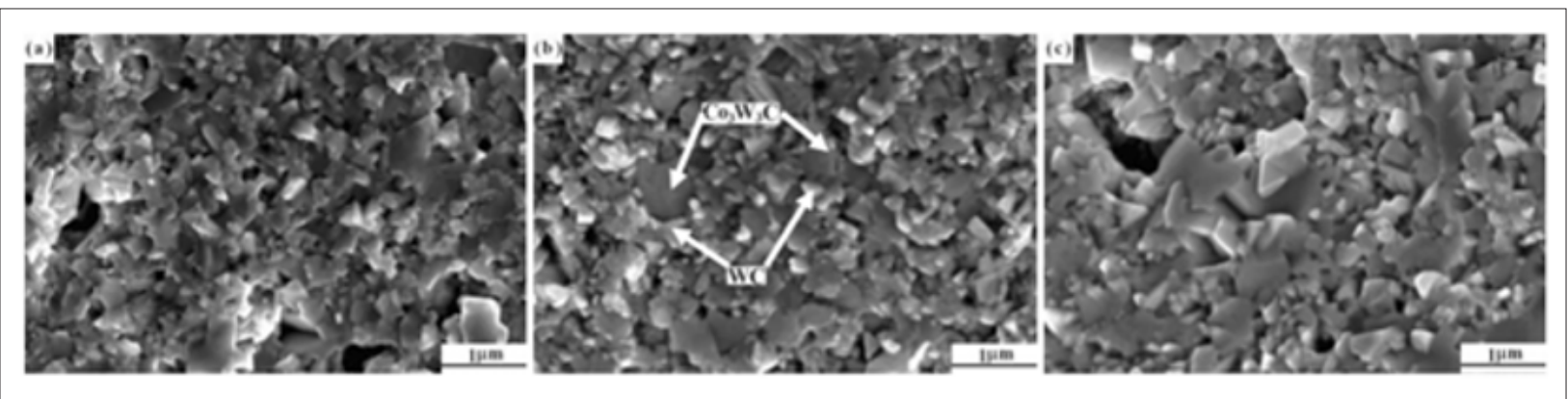

Figure 2: SEM images of fractured surface of (a) WC-6Co, (b) WC-8Co, (c) WC-10Co cemented carbide prepared at $1400^{\circ} \mathrm{C}$ in $1 \mathrm{hr}[12]$.

\section{Spark plasma sintering}

In the Spark Plasma Sintering (SPS) method the sintering is performed at lower temperatures and lasts for shorter periods than in conventional methods. The powder is heated through a pulse current, which causes spark discharges to be ignited in the pores and these discharges remove the absorbed gases and oxides from the surfaces of the particle [5]. The sintering process occurs under the influence of a current and pressure simultaneously [13]. (Figure 3) shows the relative density with respect to the crystallite size and pressure when using the SPS method to produce zirconium oxide. It is now believed that through faster and better diffusion mechanism, plasma-based sintering is able to reach theoretical density in materials [2].

\section{Pulse plasma sintering}

The work by Michalski et al. shows that pulse plasma sintering (PPS) process can be carried out at relatively low temperatures when compared to that of SPS [5]. The spark charges that are present in PPS remove the gaseous content, which enables an easier path for the bonding of the particles or grains [5]. The grain growth 
of WC in a WC-10 wt\% Co alloy obtained by sintering nanosized (5-20nm) WC-Co powder drastically increased; first observed at $200 \mathrm{~nm}$ after 30 seconds of sintering at $1400{ }^{\circ} \mathrm{C}$, and finally $2 \mathrm{~m}$ after an additional 30 seconds of sintering [6]. The source of energy for the Pulse Plasma Sintering (PPS) is a 200F capacitor battery; this heats up the powder that is held in a graphite die through periodically repeated current pulses that last several hundreds of microseconds. Due to the electrical pulses having a short duration $(500 \mu \mathrm{s})$ compared to the interval between the pulses $(0.5 \mathrm{~s}-5 \mathrm{~s})$ the average temperature of the powder being sintered is lower than the temperature reached during exposure to the current pulse [5]. The PPS process is much more intensive due to the high energy that is delivered in a pulse which is greatly larger than in the other methods' [5]. The sintering process promotes growth of tungsten carbide grain size through the presence of the liquid Co phase, this is undesirable as the mechanical properties deteriorate as the grain size increases [5]. The grain growth comes from the highrate diffusion of WC through the liquid Co phase. Smaller grain size in WC is highly desirable as it causes an increased hardness and improved mechanical properties, whereas an increase in Co binding phase equates to an increased fracture toughness but decreased hardness [5]. The fracture toughness and hardness of the WC-12 wt.\% Co carbides sintered using the pulse plasma method are shown in Figure 4. Both the fracture toughness and the hardness are observed to increase up to $1100^{\circ} \mathrm{C}$ and then decrease when the temperature is increased to $1200^{\circ} \mathrm{C}$.

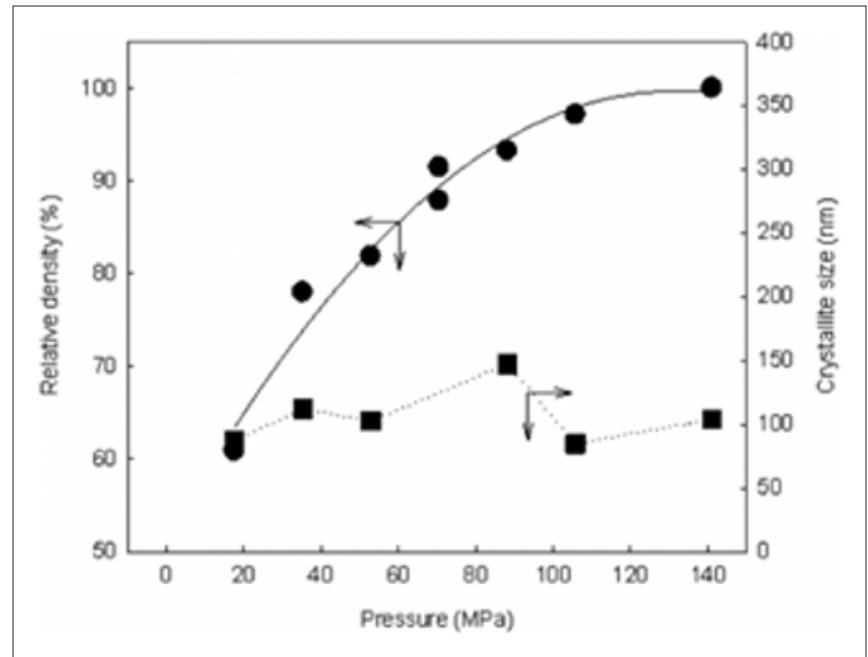

Figure 3: Effect of applied pressure on density and grain size of cubic Zirconia. Constant temperature of $1200^{\circ} \mathrm{C}$, hold time $5 \mathrm{~min}$, heating rate $200^{\circ} \mathrm{C} / \mathrm{min}[13]$.

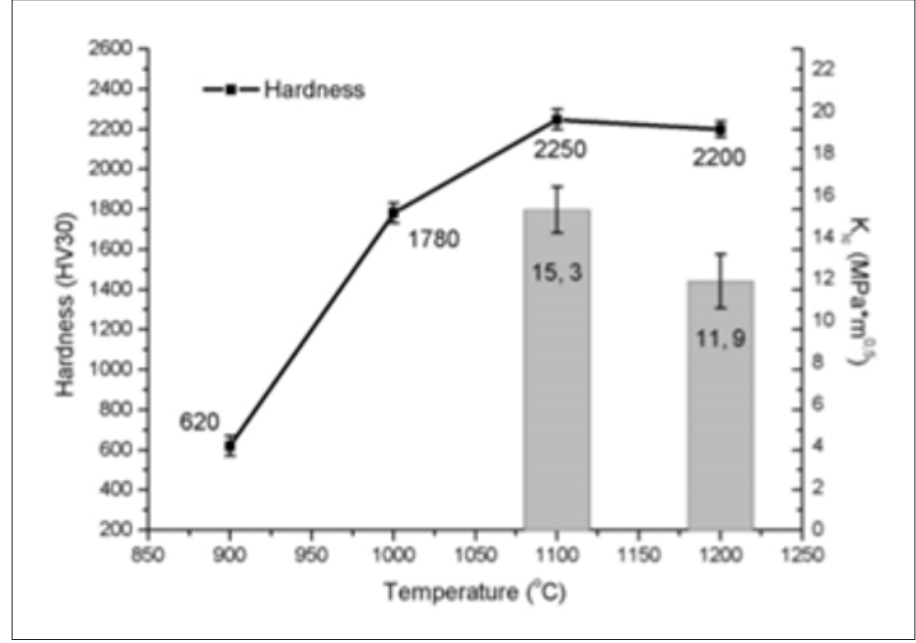

Figure 4: Variation of the hardness and fracture toughness with the sintering temperature [5].

\section{Upgraded field assisted sintering technology (U-FAST)}

U-FAST is a low voltage technology, which is the updated version of modern methods such as pulse plasma compaction. Heating up of powders in U-FAST is realized by very narrow electrical pulses. Very short current pulses below of 1 millisecond are used to heat the material, which allows producing a material with good properties such as pure WC. The U-FAST technology allows for full densification (Figure 5) in a much shorter period of time and lower temperature when compared to the other sintering methods. The shorter time and less energy consumption make this method ideal to fabricate nanocrystalline materials and submicron without unfavorable grain growth during the sintering process. The current 
impulse is shorter and the interval between impulses is shorter than that of the SPS methods, this is what facilitates the faster densification and diffusion in U-FAST. The materials produced by
U-FAST are $\mathrm{Al}_{2} \mathrm{O}_{3}$ at $1100{ }^{\circ} \mathrm{C}$, dense $\mathrm{Al}_{2} \mathrm{O}_{3}-\mathrm{ZrO}_{2}$ ceramics at 1150 ${ }^{\circ} \mathrm{C}$, dense $\mathrm{W}-\mathrm{SiO}_{2}$ composites at $1600{ }^{\circ} \mathrm{C}$, amorphous bulk metallic glasses $\mathrm{ZrCuAlNb}$ with full density without crystallization at $400^{\circ} \mathrm{C}$.

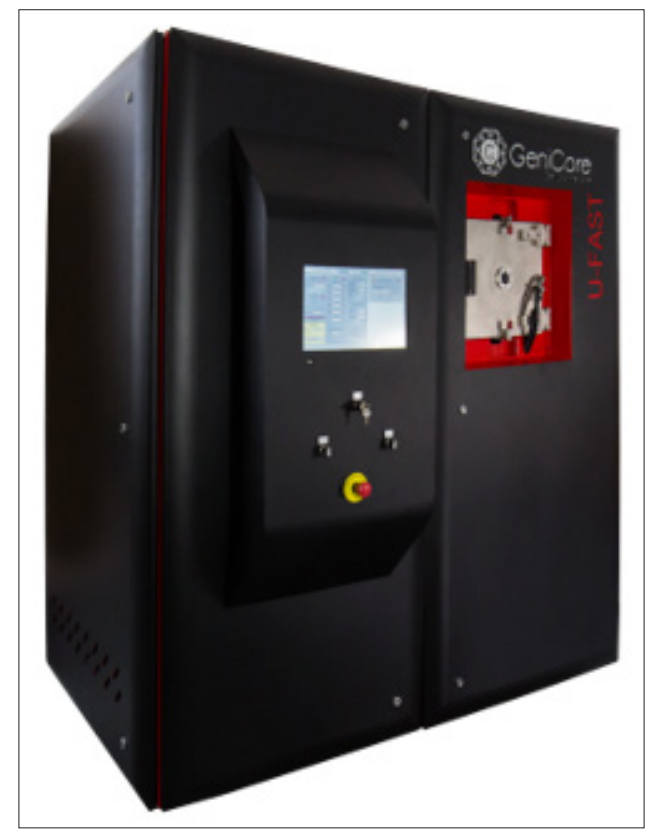

Figure 5: Image of the U-fast machine.

The advantages of new technology over the others are that its short period of time reduce the unfavourable grain growth during sintering. The sintering is performed at uniaxial pressure. One of the main benefit is its low processing temperature and low pressure without compromising the mechanical properties of the material. It can be observed from the SEM images that WC particles can bind together without any binder Figure 6. Some of the grains are closely packed which are showing complete diffusion of the interfaces of particles. The grain growth is minimal even when full densification is achieved. The high hardness was achieved in the range of 2400$2500 \mathrm{HV}$ and the fracture toughness was $15-18 \mathrm{MPa} \sqrt{\mathrm{m}}$. The UFAST technology makes it possible to synthesize pure WC without any binder and growth inhibitor, which can deteriorate the mechanical properties of material.

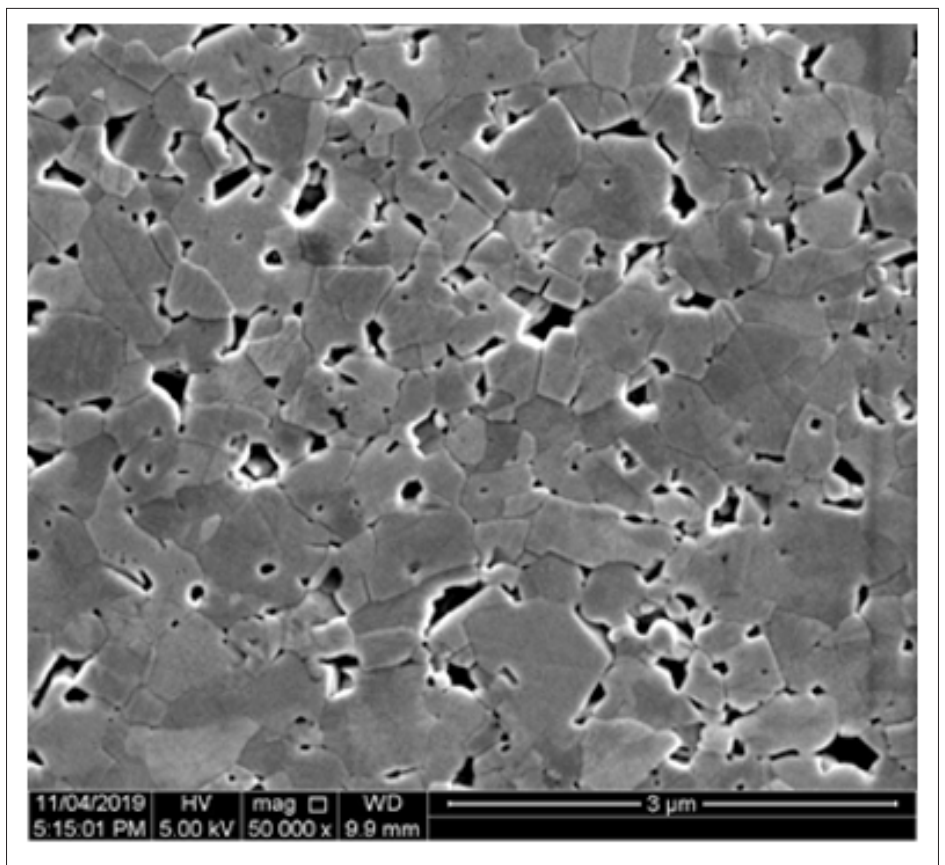

Figure 6: SEM micrograph (using SEs) of pure WC (initial particle size of 100nm) synthesized by U-FAST technology at $2000^{\circ} \mathrm{C}$ without using any binder and grain growth inhibitor. 


\section{Conclusion}

Powder metallurgy is an important part of the modern-day sintering techniques as a large variety of materials are produced from powders. The U-FAST method is highly beneficial to sintering technologies as it yields better mechanical properties of cemented carbides with more efficiency. The results achieved show very positive trends with the U-FAST sintered tungsten carbide samples yielding higher hardness values than pulse plasma compacted tungsten carbide. The tungsten carbide particles were seen to be able to bind successfully when there is no binder or grain growth inhibitor when U-FAST was used. If the use of the U-FAST method could be amplified, it would have a very positive impact on the mechanical properties of cemented carbides produced through sintering.

\section{Acknowledgment}

The authors acknowledge the expertise, equipment and support provided by Microscopy Australia and the Australian National Fabrication Facility (ANFF) at the South Australian nodes of the MA and ANFF under the National Collaborative Research Infrastructure Strategy.

\section{References}

1. Upadhyaya A, Ghosh C (2002) Effect of coating and activators on sintering of W-Cu alloys. Powder Metallurgy Progress (Slovak Republic) 2(2): 98-110.

2. Raihanuzzaman RM, Rosinski M, Xie Z, Ghomashchi R (2016) Microstructure and mechanical properties and of pulse plasma compacted WC-Co. International Journal of Refractory Metals and Hard Materials 60: 58-67.
3. Hausner HH (2012) Modern developments in powder metallurgy. Volume 3 Development and Future Prospects, Springer Science and Business Media.

4. Oghbaei M, Mirzaee O (2010) Microwave versus conventional sintering: A review of fundamentals, advantages and applications. Journal of Alloys and Compounds 494(1-2): 175-189.

5. Michalski A, Siemiaszko D, Jaroszewicz J, Rosiński M, Psoda M (2006) Nanocrystalline cemented carbides sintered by the pulse plasma method. In: Solid State Phenomena, Trans Tech Publ 114: 245-250.

6. Fang ZZ, Wang X, Ryu T, Hwang KS, Sohn H (2009) Synthesis, sintering, and mechanical properties of nanocrystalline cemented tungsten carbide-A review. International Journal of Refractory Metals and Hard Materials 27(2): 288-299.

7. Porat R, Berger S, Rosen A (1996) Sintering behavior and mechanical properties of nanocrystalline WC/Co. In: Materials Science Forum, Trans Tech Publ 225-227: 629-648.

8. Powder Metallurgy Devices 2018.

9. Breval E, Cheng J, Agrawal D, Gigl P, Dennis M, et al. (2005) Comparison between microwave and conventional sintering of WC/Co composites. Materials Science and Engineering 391(1-2): 285-295.

10. Meredith RJ (1998) Engineers' handbook of industrial microwave heating, IET.

11. Calinescu J, Martin D (2000) Microwaves involvement in materials synthesis and processing. In: Symposium Strategic Advantages of Information Technology and Technology Transfer in the Romanian Economy.

12. Liang BL, Ai YL, Liu CH, Jiang N (2013) Mechanical properties of WC-Co cemented carbide prepared via vacuum sintering. In: Applied Mechanics and Materials, Trans Tech Publ 275-277: 1917-1920.

13. Munir Z, Anselmi TU, Ohyanagi M (2006) The effect of electric field and pressure on the synthesis and consolidation of materials: A review of the spark plasma sintering method. Journal of Materials Science 41(3): 763-777. 